\title{
Warty gastric cancer with polypoid metastases to the gallbladder and urinary bladder
}

This article was published in the following Dove Press journal:

Gastrointestinal Cancer:Targets and Therapy

6 September 2013

Number of times this article has been viewed

\author{
Mutsushi Matsuyama ${ }^{1,2}$ \\ Kazuo Kato ${ }^{3}$ \\ Seiichi Goto ${ }^{4}$ \\ Suzuko Moritani ${ }^{5}$ \\ Kazuhiro Sentani ${ }^{6}$ \\ Makoto Kuroda ${ }^{7}$ \\ 'Clinical Laboratory, Hekinan \\ Municipal Hospital, Hekinan, Aichi, \\ ${ }^{2}$ Department of Cell Biology and \\ Anatomy, Fujita Health University \\ School of Medicine, Toyoake, Aichi, \\ ${ }^{3}$ Clinical Laboratory, Rousai Hospital, \\ Nagoya, Aichi, ${ }^{4}$ Department of \\ Internal Medicine, Hekinan Municipal \\ Hospital, Hekinan, Aichi, ${ }^{5}$ Department \\ of Advanced Diagnosis, Division \\ of Pathology, National Hospital \\ Organization, Nagoya Medical \\ Center, Nagoya, Aichi, ${ }^{6}$ Department \\ of Molecular Pathology, Hiroshima \\ University Graduate School of \\ Biomedical Sciences, Hiroshima, \\ ${ }^{7}$ Department of Diagnostic Pathology, \\ Fujita Health University School of \\ Medicine, Toyoake, Aichi, Japan
}

Correspondence: Kazuo Kato Clinical Laboratory, Rousai Hospital, Nagoya, Aichi 455-8530, Japan

Tel +8I $05265255 \mathrm{II}$

Fax +81 0526525953

Email kato.pat@chubuh.rofuku.go.jp

\begin{abstract}
An 80-year-old man had severe lumbago that was diagnosed as multiple myeloma. He was treated with melphalan, prednisone, and zoledronic acid, with a good response. However, he had severe anemia, and endoscopic examination revealed gastric cancer. He died 3 months later. Autopsy revealed verrucous gastric cancer consisting of numerous polypoid mucosal excrescences that had metastasized to the gallbladder and urinary bladder, showing similar polypoid mucosal lesions. The cancer consisted of poorly differentiated cells (about 85\%) and signet ring cells $(15 \%)$ in the stomach. The cancerous tissue was not associated with a desmoplastic reaction, and the signet ring cells showed a positive reaction to cytokeratin 7 and regenerating islet-derived family member 4 antibodies. The cancer cells had a propensity to proliferate on the mucosal surface of the stomach, gallbladder, and urinary bladder.
\end{abstract}

Keywords: warty gastric cancer, polypoid metastases, signet ring cells, cytokeratin 7, regenerating islet-derived family member 4

\section{Introduction}

Aggressive types of gastric cancer do not show warty features in the stomach and do not metastasize as polypoid tumors. Gastric cancers rarely metastasize to the gallbladder or urinary bladder. ${ }^{1,2}$ However, we encountered a case of warty gastric cancer that metastasized to the gallbladder and urinary bladder, and showed unusual polypoid mucosal excrescences.

\section{Case report}

This 80-year-old man had initially presented to hospital 4 years earlier complaining of lumbago. A fracture of the second lumbar vertebrae was detected on radiologic examination. The grade of lumbago worsened and his serum IgG level increased to $5,328 \mathrm{mg} / \mathrm{dL}$. He was referred to us 2 years later and was diagnosed to have symptomatic multiple myeloma. He was treated with melphalan, prednisone, and zoledronic acid. The response to treatment was good, and he later reached the plateau phase. However, he was admitted to our hospital with anorexia and general fatigue. He had progressive anemia, and endoscopy showed warty gastritis and a shallow gastric ulcer at the angle (Figure 1A). Biopsies taken from both sites revealed poorly differentiated adenocarcinoma with signet ring cells. Computed tomography of the chest, abdomen, and pelvis for evaluation of tumor spread showed only slight enlargement of a lymph node at the lesser curvature of the stomach. We considered that curative gastrectomy was possible. However, taking into consideration his advanced age, poor performance status, and concomitant myeloma, surgery was considered to be high risk. Ultimately the patient 

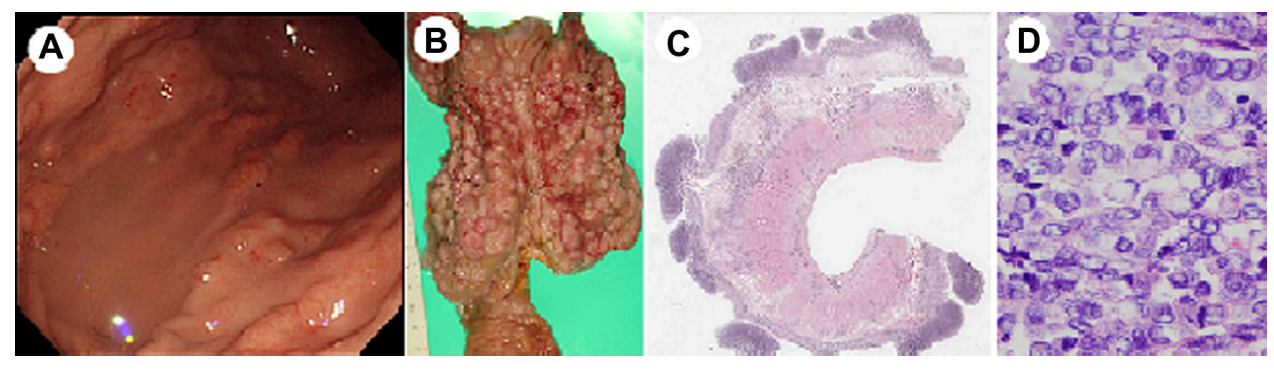

Figure I (A) Endoscopic imaging of the stomach showing numerous elevated lesions. (B) Macroscopic imaging of the gastric cancer showing numerous warty lesions. (C) Histologic section of part of the stomach showing numerous cancer protrusions (hematoxylin-eosin staining, $2.3 \times$ ). The surface of the mucosa was overturned by contracture of the muscle layers by fixation. (D) Higher magnification of one of the cancer nodules shown in (C) (hematoxylin-eosin staining, $310 \times$ ).

refused surgery. His symptoms were relieved by administration of a proton pump inhibitor. Chemotherapy for myeloma was stopped, but he remained in the plateau phase. About 8 weeks later, he complained of severe weakness. Clinical evaluation showed anemia, renal failure, disseminated intravascular coagulation, rapid progression of gastric cancer, and cancerous peritonitis. Soon afterwards, he died of multiple organ failure.

Autopsy revealed numerous warty mucosal excrescences in the stomach, measuring up to $13 \mathrm{~mm}$ (Figure 1B and C). These warty excrescences occupied almost all of the gastric mucosa (Figure 1C), and consisted of poorly differentiated adenocarcinoma cells and signet ring cells (Figure 1D). A shallow linear erosive lesion was seen in the lesser curvature (Figure 1B). Microscopic nests of carcinoma were observed in the lymph vessels of the submucosal, muscular, and subserosal layers, resulting in peritonitis carcinomatosa. No desmoplastic changes were observed around the carcinoma cells. Normal fundic and pyloric mucosa intervened between the polypoid mucosal tumors, and showed no intestinal metaplasia. Ascites measured about $1500 \mathrm{~mL}$. Small cancerous nests were also observed in the small and large intestines, gallbladder (Figure 2A and B), adrenals, urinary bladder (Figure 2C), and heart. In the gallbladder, numerous minute cancerous nodules were found on the surface mucosal areas, and the mucosal appearance resembled that in the stomach. Histologically, each cancer nodule consisted of undifferentiated cells intermingled with a few signet ring cells located beneath the attenuated non-neoplastic epithelial cells. No macroscopic swelling was found in the regional lymph nodes, but microscopic metastases were found in these and the hilar lymph nodes. Several small cancerous nests were found just beneath the transitional epithelium of the urinary bladder (Figure 2C). In the heart, small metastatic foci were found in the pericardial fatty tissue and between the myocardial muscle bundles. Numerous small clusters of carcinoma cells were also observed in the bone marrow of the sternum. However, no carcinoma metastases were found in the liver, spleen, and lungs. The spleen weighed only $20 \mathrm{~g}$, but infiltration of myeloma cells was detected.

Immunohistochemically, almost all the cancer cells were positive for PAS, CAM5.2, AE1/AE3, CEA, and CK. The signet ring cells were positive for cytokeratin 7 (Figure 3A) and regenerating islet-derived family member 4 (Reg IV, Figure 3B). Endocrine markers, such as synaptophysin and chromogranin A, were negative. No Helicobacter pylori was detected in the stomach, duodenum, or jejunum.
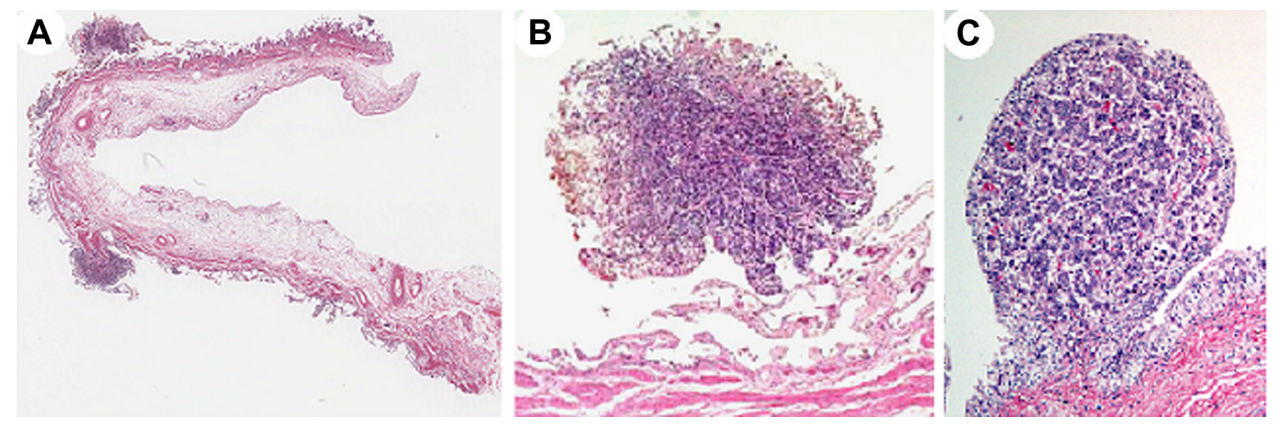

Figure 2 (A) Two metastatic foci of gastric cancer in the gallbladder (hematoxylin-eosin staining, 32x). (B) A warty metastatic focus of gastric cancer in the gallbladder, in which the surface was covered by flattened epithelial cells of the organ (hematoxylin-eosin staining, I03x). (C) A polypoid metastatic focus of gastric cancer in the urinary bladder, where the surface was covered by flattened epithelial cells of the organ (hematoxylin-eosin staining, 103x). 


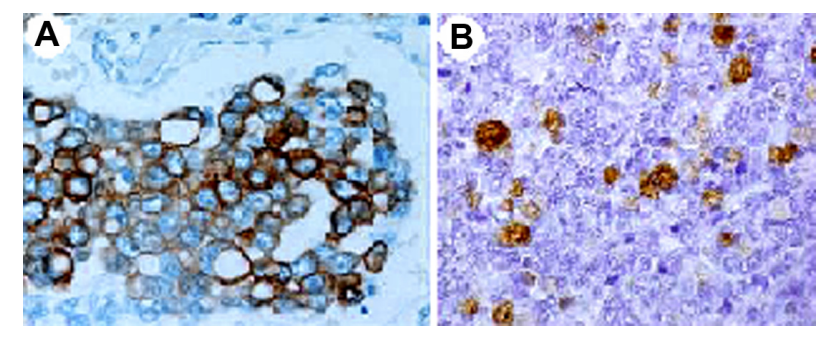

Figure 3 Signet ring cells showing a strongly positive reaction against (A) cytokeratin 7 and (B) regenerating islet-derived family member 4 antigens (3I0X).

\section{Discussion}

The warty appearance of the mucosal surface of the stomach in the present case is unique. The number of warty nodules increased very rapidly after endoscopic examination was performed ( 11 weeks before the patient's death). The multiple polypoid masses reminded us of metastatic gastric carcinoma from other organs. However, no macroscopic tumors were detected in other organs. Immunohistochemical examination of the tumors showed that the cytoplasm of the signet ring cells was strongly positive for cytokeratin 7 and mucous granules for Reg IV. Expression of Reg IV was limited to the normal epithelial and cancerous cells of the stomach, small intestine, colon, and pancreas. ${ }^{3}$ The finding of positivity for cytokeratin 7 and Reg IV as well as the absence of macroscopic tumor in the small intestine, colon, and pancreas, enabled us to rule out the possibility of metastatic cancer and confirmed the present case as primary gastric carcinoma.

Metastatic lesions in this patient were also morphologically characteristic. The lamina propria mucosa of the gallbladder and urinary bladder lacked elaborated blood and lymphatic vessels, so it was assumed that carcinoma cells had penetrated in the vascular plexus and mesenchymal stroma to reach the uppermost layer of the mucosa through loose connective tissue, showing the peculiar tropism of the cancer cells to the surface of the mucosa. Tumor cells of primary signet ring cell carcinoma of the gallbladder infiltrate the lamina propria, leaving the covering epithelium intact. ${ }^{1}$ Some carcinoma cells of the stomach and kidneys have a strong affinity for the mucosal surfaces of the gallbladder and urinary bladder. ${ }^{2}$ Tumor cells of oral malignant melanoma have tropism for the surface epithelium. ${ }^{4}$ Our previous study in mice showed that carcinoma cells of the duodenum, induced by oral administration of N-ethyl-N'-nitro$\mathrm{N}$-nitrosoguanidine, move to the surface of the villi. ${ }^{5}$ Cells of human signet ring carcinoma of the gallbladder infiltrate the lamina propria, leaving the covering epithelium intact. ${ }^{1}$ The assumption can be made that the carcinoma cells in our patient had special surface substances with an affinity for the epithelial cells of various organs.

\section{Conclusion}

Numerous polypoid metastases in the gallbladder and urinary bladder in this case of gastric cancer indicated that the cancer cells had an affinity for the surface mucosal cells of the vesicular organs.

\section{Disclosure}

The authors report no conflicts of interest in this work.

\section{References}

1. Albores-Saavedra J, Henson DE, Klimstra DS. Signet ring cell carcinoma, pathology of invasive carcinoma of gallbladder, tumors of the gallbladder, extrahepatic bile ducts, and ampulla of Vater. In: Atlas of Tumor Pathology, 3rd Series. Washington, DC: Armed Forces Institute of Pathology; 2000.

2. Goldstein AG. Metastatic carcinoma of the bladder. J Urol. 1967;98: 209-215.

3. Sentani K, Oue N, Tashiro T, et al. Immunohistochemical staining of Reg IV and claudin-18 is useful in the diagnosis of gastrointestinal signet ring cell carcinoma. Am J Surg Pathol. 2008;32:1182-1189.

4. Patel SG, Prasad ML, Escrig M, et al. Primary mucosal malignant melanoma of the head and neck. Head Neck. 2002;24:247-257.

5. Matsuyama M, Nakamura T, Suzuki H, et al. Early lesions in carcinogenesis by N-ethyl-N'-nitro-N-nitrosoguanidine in mouse duodenum. In: Farber E, Kawachi, T, Nagayo T, et al, editors. Pathophysiology of Carcinogenesis in Digestive Organs. Tokyo, Japan: University of Tokyo Press; 1977.

\section{Publish your work in this journal}

Gastrointestinal Cancer: Targets and Therapy is an international, peer-reviewed, open access journal focusing on gastro-intestinal cancer research, identification of therapeutic targets and the optimal use of preventative and integrated treatment interventions to achieve improved outcomes, enhanced survival and quality of life for the

\section{Dovepress}

cancer patient. The manuscript management system is completely online and includes a very quick and fair peer-review system. Visit http://www.dovepress.com/testimonials.php to read real quotes from published authors. 